\title{
Oficina de leitura e escrita para estudantes da Educação de Jovens e Adultos: a relevância da biblioteca escolar como recurso pedagógico
}

\author{
Reading and writing workshop for Youth and Adult Education students: the relevance of the \\ school library as a pedagogical resource
}

\author{
Anderson L. Azevedo \\ Doutorando em História pela Universidade do Estado do Rio de Janeiro - UERJ, Brasil. \\ Bibliotecário da Fundação Oswaldo Cruz - Fiocruz, Brasil. \\ https://orcid.org/0000-0003-2787-0236 \\ E-mail: anderson.azevedo@fiocruz.br
}

\section{Resumo}

O objetivo deste artigo é apresentar um relato de experiência sobre o desenvolvimento da Oficina de Leitura e Escrita para estudantes da Educação de Jovens e Adultos, na Biblioteca Emília Bustamante da Escola Politécnica de Saúde Joaquim Venâncio, da Fundação Oswaldo Cruz, cidade do Rio de Janeiro. Para tanto, apresentam-se primeiramente um panorama do analfabetismo no Brasil, de acordo com informações do Instituto Brasileiro de Geografia e Estatística em 2019, e as determinações da Lei de Diretrizes e Bases da Educação Nacional para mitigar essa defasagem social. Em seguida, são apresentados os conceitos da Educação de Jovens e Adultos, a importância da leitura e da escrita e a definição de biblioteca escolar. Por último, são analisados os relatos da professora de língua portuguesa, do coordenador do curso e dos bibliotecários que acompanharam o desenvolvimento da Oficina e os resultados obtidos. De acordo com esses profissionais, observou-se que os alunos participantes apresentaram avanços no desempenho dentro e fora da sala de aula, com melhora significativa na interpretação de textos, escrita e até na dicção. Como conclusão, a experiência comprova a importância da leitura e da escrita na vida em sociedade do indivíduo e a relevância da biblioteca escolar como recurso pedagógico no desenvolvimento da capacidade de letramento e na formação de um sujeito crítico, que busca expandir suas experiências existenciais de acordo com sua realidade e vivências.

Palavras-chave: Biblioteca escolar. Leitura. Escrita. Educação de jovens e adultos.

\begin{abstract}
The purpose of this article is to present an experience report on the development of the Reading and Writing Workshop for students of Youth and Adult Education, at Joaquim Venâncio Polytechnical School of Health Library - Emília Bustamante, from Oswaldo Cruz Foundation in Rio de Janeiro. To this end, an overview of illiteracy in Brazil appears first, according to information from Brazilian Institute of Geography and Statistics in 2019 and the Law of Directives and Bases of National Education determinations to mitigate this social gap. Then, the concepts of Youth and Adult Education, the importance of reading and writing and the definition of the school library are ordered. Finally, the reports from the Portuguese language teacher, the course coordinator and the librarians who followed the development of the Workshop and the results obtained are analyzed. According to these professionals, it was observed that the participating students showed advances in performance inside and outside the classroom, with a significant improvement in interpretation of texts, writing and even in diction. In conclusion, the experience proves the importance of reading and writing in the individual's life in society and the impact of the school library as a pedagogical resource in the development of literacy capacity and in the formation of a critical person, who seeks to expand his existential experiences according to his reality and experiences.
\end{abstract}

Keywords: School library. Reading. Writing. Youth and adult education. 


\section{Introdução}

No Brasil, de acordo com o Instituto Brasileiro de Geografia e Estatística (IBGE, 2019), em 2018, 11,3 milhões de pessoas com 15 anos ou mais de idade, representando 6,8\% da população, são analfabetas. Na faixa etária dos 60 anos ou mais, esse número se aproxima de 6 milhões, correspondendo a 18,6\% da população. Ainda, ao se considerarem pessoas com 25 anos ou mais de idade, 6,9\% desses indivíduos não têm qualquer grau de instrução, e $33,1 \%$ apresentam o Ensino Fundamental incompleto.

Essas pessoas, por diferentes motivos, não tiveram acesso à escola ou se viram impedidas de frequentá-la na idade adequada. Para esses indivíduos, a Lei de Diretrizes e Bases da Educação Nacional (LDBEN) determina a oferta de cursos gratuitos nos níveis Fundamental e Médio, visando favorecer a "[...] educação e a aprendizagem ao longo da vida" (BRASIL, 1996). Esses são cursos com características especiais, com vistas a atender às especificidades desse "[...] alunado, seus interesses, condições de vida e de trabalho" (BRASIL, 1996).

De acordo com Aguiar e Andrade Neta (2015, p. 9), a Educação de Jovens e Adultos (EJA) tem as seguintes funções: reparadora, que se refere ao reconhecimento de que esses indivíduos têm direito a uma educação de qualidade e de acordo com suas necessidades específicas; equalizadora, uma vez que visa promover “[...] o restabelecimento da trajetória escolar do educando, possibilitando-lhe igualdade de oportunidades e novas possibilidades de convívio e participação social"; e função qualificadora, que diz respeito à aquisição e atualização de saberes orientados pela determinação da LDBEN de que a educação deve se dar ao longo da vida.

A Fundação Oswaldo Cruz (Fiocruz), em parceria com a Oscip (Organização da Sociedade Civil de Interesse Público Local) denominada Rede CCAP, oferece o curso de Educação de Jovens e Adultos (EJA), sob orientação e certificação da Escola Politécnica de Saúde Joaquim Venâncio (EPSJV), nos níveis Fundamental e Médio. Além das disciplinas obrigatórias de cada nível, os cursos ofertam oficinas integradoras, entre as quais a Oficina de Leitura e de Escrita. Participam dessas oficinas todos os alunos da EJA, sem a separação em turmas que ocorre habitualmente nas disciplinas obrigatórias. Os alunos escolhem, de acordo com seu interesse, a oficina de que participarão (FIOCRUZ; EPSJV; REDE CCAP, [201-]). 
Oficina de leitura e escrita para estudantes da Educação de Jovens e Adultos: a relevância da biblioteca escolar como recurso pedagógico

Este texto objetiva apresentar a experiência da Oficina de Leitura e de Escrita promovida pela Escola Politécnica de Saúde Joaquim Venâncio, da Fundação Oswaldo Cruz, realizada na Biblioteca Emília Bustamante (BEB) e direcionada aos alunos da Educação de Jovens e Adultos dos níveis de Ensino Fundamental e Ensino Médio.

A descrição da oficina e os resultados já percebidos são apresentados por meio de relatos da professora de língua portuguesa responsável por sua realização, do coordenador da EJA e dos bibliotecários da BEB.

\section{A leitura e a EJA}

Um dos conceitos de "leitura" encontrado atualmente em Houaiss (2009) é descrito como ato de decifrar e aprender um conteúdo de um texto escrito. A leitura contribui para a formação do indivíduo na medida em que possibilita a transmissão de informações e conhecimentos, permitindo que ele analise o seu cotidiano e o mundo que o cerca. A leitura favorece a compreensão de fatos e eventos, além de promover maior criticidade na análise das

diferentes versões sobre fatos que são divulgados por veículos de comunicação. É por meio da leitura que o indivíduo adquire o domínio da linguagem e conjuga leitura e escrita, o que influencia todas as áreas do conhecimento (KRUG, 2015).

O homem em busca da realização pessoal necessita da leitura pelo fato de ela deter algumas funções que se relacionam com o cognitivo, o afetivo, além da dimensão estética e criativa. Somam-se a essas funções específicas outra tão importante como as anteriores: a função social. A leitura possibilita ao indivíduo a abertura de uma visão de mundo ampliada, tornando-o receptivo ao intercâmbio com outras pessoas, conscientizando-o do seu papel na sociedade em que se encontra inserido (MARQUEZ, 1991).

Corroborando o exposto, Lamas (1993, p. 168) afirma que "A leitura é, tal como a vida, de natureza dialógica. Pela leitura o ser humano interroga o texto, interroga o mundo, interroga-se a si próprio, procura respostas, levanta dúvidas e entra, assim, na grande orquestração do universo". É pela leitura que o indivíduo conhece o outro e o mundo, e se dá a conhecer.

Aguiar e Andrade Neta (2015) ressaltam que a contemporaneidade envolve e exige de todos os indivíduos a habilidade de leitura para compreensão das situações e atividades 
rotineiras, como, por exemplo, sinalização das vias de tráfego, indicação de ruas e avenidas, condições de vendas de produtos, acesso a serviços, dentre outras.

Ainda que o indivíduo, durante seus primeiros anos de vida, tenha contato com "objetos de leitura", é a escola que lhe proporciona a alfabetização, que lhe permite codificar e decodificar símbolos, formando e entendendo as ideias expressas. Campello (2015) acrescenta que a ausência da biblioteca escolar e a falta de acesso e uso de livros, entre outros materiais informativos para estudantes nas fases iniciais de ensino, pode causar prejuízos no letramento do sujeito.

O letramento é um estado, uma condição: o estado ou condição de quem interage com diferentes portadores de leitura e de escrita, com diferentes gêneros e tipos de leitura e de escrita, com as diferentes funções que a leitura e a escrita desempenham em nossa vida. Enfim: letramento é o estado ou condição de quem se envolve nas numerosas e variadas práticas de leitura e escrita (SOARES, 1998, p. 44).

Contudo, somente a fase de alfabetização e os primeiros anos de estudo não bastam para que o indivíduo desenvolva tais habilidades; isso o restringe à decifração de tais símbolos, sem permitir que ele desenvolva a criticidade necessária para a compreensão aprofundada das ideias (AGUIAR; ANDRADE NETA, 2015).

Ademais, a leitura interfere positivamente no desenvolvimento da escrita. De acordo com Fouani e Coito (2013, p. 4), o aluno da EJA, devido ao seu precoce afastamento do ensino formal, apresenta dificuldades específicas de leitura, especialmente em relação a vocabulário, “[...] sintaxe, utilização de metáforas, desconhecimento de termos técnicos, falta ou excesso de imagens, textos fragmentados que comprometem a compreensão do texto, entre outros".

Os referidos autores salientam que a realidade brasileira, especialmente em relação aos alunos da EJA, mostra que a leitura ocorre quase que de maneira funcional, pautada na associação de letras e sílabas. Essa situação impõe a esses indivíduos uma situação de analfabetismo funcional, limitando sua capacidade de compreensão, reflexão e crítica às informações que recebe (FOUANI; COITO, 2013).

De acordo com Sousa, Cancela e Machado (2017), os alunos da EJA são diferenciados daqueles que frequentam o ensino regular, uma vez que já são adultos e trazem consigo uma bagagem de vida definida pelo seu desenvolvimento na sociedade; não raro, têm famílias constituídas; trabalham durante o dia e estudam à noite, quando já estão cansados; e carregam crenças e valores próprios dos meios em que convivem, entre outros aspectos. Os autores 
Oficina de leitura e escrita para estudantes da Educação de Jovens e Adultos: a relevância da biblioteca escolar como recurso pedagógico

analisam também que dificuldades adicionais surgem das condições em que ocorre o ensino da EJA, sendo frequente que os próprios professores não tenham o hábito de leitura e que se apeguem ao conteúdo e a práticas dos livros didáticos; como se não bastasse, muitas escolas não dispõem de biblioteca para oferecer aos alunos livros e um espaço adequado para a leitura.

Concordando com essa afirmativa, Bezerra (2009) observa que os alunos da EJA têm uma visão de mundo peculiar devido às suas experiências, que moldaram suas crenças e valores. Esses indivíduos buscam recuperar o tempo perdido, relembrar o já estudado nos anos anteriores, como também se atualizar, adquirindo novos conhecimentos, e se preparar para que consigam se integrar no mundo atual.

Desse modo, a leitura deve ser diversificada, incluindo textos literários, com o intuito de permitir a esse aluno desenvolver a imaginação, a compreensão e a percepção das intenções do autor, ao mesmo tempo em que formula as suas próprias considerações, envolvendo a compreensão de épocas e culturas distintas, entre outros aspectos. A literatura amplia, assim, a capacidade de análise e de crítica, bem como aumenta a capacidade argumentativa, favorecendo a percepção de mundo e do contexto em que o leitor se encontra inserido (SOUSA; CANCELA; MACHADO, 2017).

Há ainda que se considerar que a produção de conhecimento possibilitou a evolução da sociedade e, para Santa Anna (2017, p. 36), a leitura é “[...] uma estratégia para gerar conhecimento", pois proporciona o desenvolvimento de atitudes, habilidades e competências que interferem no dia a dia dos indivíduos, propiciando condições para a solução de problemas e desafios impostos pela vida.

\section{A biblioteca escolar}

A biblioteca escolar se encontra integrada em uma unidade educacional, e atende aos diferentes níveis de ensino: Pré-Escolar, Fundamental e Médio, visando ao suporte à comunidade de alunos, professores e trabalhadores ali inseridos. Em alguns casos, ela estende seus serviços aos familiares de alunos e à comunidade externa local. 
Ainda sobre a biblioteca escolar, Fragoso (2002) indica duas importantes finalidades básicas dessas instituições, quais sejam: a educativa, em que reforça a ação de alunos e professores; e a cultural, em que colabora para a educação informal dos indivíduos.

Ao se referir ao papel da biblioteca, Queiroz (2006, p. 51) acrescenta que, no âmbito educacional, compete à biblioteca um importante papel, resultado da sua contribuição à educação, representando tal núcleo "[...] um suporte, indispensável à educação e cidadania, [...] como fonte de conhecimento e de informação insubstituível, um imprescindível depositário do saber". Para o autor, é indissociável a relação entre biblioteca e educação.

A biblioteca escolar pode sim ser o local onde se forma o leitor crítico, aquele que
seguirá vida afora buscando ampliar suas experiências existenciais através da leitura.
Mas, para tanto, deve ser pensada como um espaço de criação e de
compartilhamento de experiências, um espaço de produção cultural em que crianças
e jovens sejam criadoras e não apenas consumidoras de cultura (CARVALHO,
2003, p. 22).

Importante ressaltar a importância do bibliotecário não só como aquele que trata, organiza e dissemina a informação, ou que desenvolve as habilidades informacionais necessárias para a busca e recuperação de informações, mas também como o profissional capacitado para trabalhar o desenvolvimento da leitura e escrita dos usuários. Silva e Ventorim (2016) defendem inclusive a parceria entre bibliotecários e professores, "numa ação conjunta e colaborativa, com o objetivo de possibilitar o ensino e a aprendizagem com um olhar voltado para as questões do contexto escolar." Para Campello (2003, p. 11), "Trabalhando em conjunto, professores e bibliotecários planejarão situações de aprendizagem que desafiem e motivem os alunos, acompanhando seus progressos, orientando-os e guiandoos no desenvolvimento de competências informacionais cada vez mais sofisticadas”.

Está comprovado que bibliotecários e professores, ao trabalharem em conjunto, influenciam o desempenho dos estudantes para o alcance de maior nível de literacia ${ }^{1}$ na leitura e escrita, aprendizagem, resolução de problemas, uso da informação e das tecnologias de comunicação e informação. (IFLA, 2000, p. 2)

Diante do exposto, fica evidente a relevância da biblioteca escolar como recurso pedagógico e social no contexto educacional e no processo de aprendizado e desenvolvimento do indivíduo. Docentes e bibliotecários devem explorar esse espaço como um importante instrumento de incentivo à leitura e escrita. Um espaço com múltiplas funcionalidades

\footnotetext{
${ }^{1}$ De acordo com Kishimoto (2010), no Brasil, a tradução de Literacy por letramento é atribuída a Mary Kato, em 1986, sendo que o termo tem sido usado de maneira abrangente nas discussões e na literatura dos educadores brasileiros. Em Portugal, por outro lado, usa-se o termo literacia precoce ou emergente, enquanto que os países latino-americanos de língua espanhola optam por alfabetización temprana (KISHIMOTO, 2010 apud HOMMERDING, 2016, p. 34).
} 
Oficina de leitura e escrita para estudantes da Educação de Jovens e Adultos: a relevância da biblioteca escolar como recurso pedagógico

educacionais, indo além do acervo e do uso das tecnologias informacionais, impactando a vida do usuário individual e coletivamente. 


\section{A oficina de leitura e escrita na Biblioteca Emília Bustamante}

A EJA da EPSJV conta com 176 estudantes, sendo 62 (35,23\%) do Ensino Fundamental e 114 (64,77\%) do Ensino Médio. Em pesquisa realizada por Azevedo e Duarte (2019), com uma mostra de 120 desses alunos, constatou-se que a idade varia entre 16 e 80 anos, com predomínio de indivíduos com idades mais elevadas no Ensino Fundamental, variando entre 36 e 55 anos, enquanto no Ensino Médio predominam as faixas etárias mais jovens, ou seja, entre os 16 e os 45 anos. Em relação ao sexo, 67,86\% dos alunos da EJA Fundamental e 76,56\% da EJA Ensino Médio são do sexo feminino. Esse perfil é consistente com a literatura, que indica que os alunos da EJA Fundamental, em geral, são mais velhos do que os da EJA Ensino Médio, confirmando as dificuldades enfrentadas pelos indivíduos mais velhos em relação ao acesso e à manutenção da vida escolar em idade adequada (AGUIAR; ANDRADE NETA, 2015).

A Oficina de Leitura e Escrita acontece no interior da Biblioteca Emília Bustamante, localizada na Escola Politécnica de Saúde Joaquim Venâncio, da Fundação Oswaldo Cruz, em Manguinhos, Rio de Janeiro. A biblioteca, ao longo dos anos, acumulou um acervo de 16.880 obras, oferecendo suporte à educação em diversos níveis de ensino. A cada ano, o acervo disponível cresce cerca de $5,7 \%$, por meio de doações e de novos trabalhos acadêmicos, por lançamentos de publicações próprias ou por aquisições. O fluxo médio de usuários por mês é de 1.533,33 usuários, que realizam consultas no local ou tomam por empréstimo as obras. A BEB constitui, assim, um espaço em que os usuários encontram os recursos e as obras necessárias para o aprimoramento de sua educação e a consecução de seus cursos.

A BEB funciona de segunda a sexta-feira, das $7 \mathrm{~h}$ às $20 \mathrm{~h}$, oferecendo, entre outros, os seguintes serviços: ambiente de pesquisa virtual, todos com acesso à internet, o que possibilita a realização de pesquisas e a elaboração de trabalhos acadêmicos; empréstimo de obras, domiciliar ou para uso em sala de aula, para alunos, estagiários, bolsistas e funcionários da Fiocruz devidamente cadastrados; consulta local ao acervo, mediante acesso do próprio usuário às estantes ou com auxílio de um funcionário da biblioteca; consulta on-line do acervo, por meio de dois terminais localizados no primeiro andar; guarda-volumes disponíveis para os usuários durante sua permanência na BEB; locais apropriados para estudo individual ou em grupo; sala de multimídia e videoconferência equipada com DVD player, videocassete, computador e TV de 42”, com capacidade para 25 pessoas; e serviço de referência capacitado a orientar os usuários em relação 
Oficina de leitura e escrita para estudantes da Educação de Jovens e Adultos: a relevância da biblioteca escolar como recurso pedagógico

ao acesso e uso de fontes de informação, por meio de aulas e treinamentos, e também para pesquisas em bases de dados e bibliotecas virtuais (AZEVEDO; ANTELO; AZEREDO, 2017).

O Dicionário Houaiss (2009) define o termo "roda" como círculo ou peça circular que gira em torno de um eixo ou ainda grupo de pessoas dispostas em círculo. Nessa perspectiva, Braun, Moraes, Oliveira e Almeida (2009) compreendem a roda literária a partir da organização de um círculo entre os alunos, preferencialmente afastados das mesas e cadeiras, como uma forma de dinamizar o aprendizado em torno de um livro previamente lido em casa. Esse tipo de exercício é uma das muitas atividades possíveis realizadas para estimular o hábito da leitura e, consequentemente, o gosto pela leitura. Além disso, representa no cotidiano uma oportunidade de diálogo, intercâmbio de conhecimento, pesquisa e aprendizado entre os participantes.

A professora de língua portuguesa responsável pela Oficina de Leitura e de Escrita dos alunos da EJA apresenta um relato da evolução da oficina e dos alunos. O objetivo da proposta é fazer com que os alunos leiam melhor, façam a interpretação de textos, saibam elaborar críticas e debater ideias. A oficina começou em fevereiro de 2019. A atividade ocorre duas vezes por semana, às terças e quintas-feiras, com duração de 50 minutos em cada dia. $\mathrm{O}$ projeto já foi iniciado anteriormente, porém foi suspenso para a introdução de outros tipos de oficinas, tendo retornado no referido ano. Nessa atividade, há liberdade para trabalhar de acordo com o desenvolvimento e interesse demonstrado pelos alunos, não havendo, portanto, qualquer direcionamento para a oficina na EJA.

Dessa forma, a professora não se prende a um livro específico, como, por exemplo, livro didático da disciplina de língua portuguesa. O trabalho é realizado a partir de poemas e textos que abordam a realidade dos alunos, porque isso facilita a compreensão deles e promove uma troca de experiência mais significativa entre esses estudantes. Algumas vezes a professora traz os textos a serem trabalhados; em outras, solicita que os alunos tragam materiais sobre uma temática definida ou sobre algum assunto que lhes chame a atenção e que gostariam de discutir. A EJA, aproveitando o acervo da biblioteca, costuma trabalhar com a literatura local, inclusive com clássicos da literatura. Como exemplo da diversidade de textos utilizados, podem ser citados poemas de Cora Coralina, Conceição Evaristo e Ferreira Goulart. Foram trabalhadas também letras de músicas dos mais diversos compositores, notícias de jornal e crônicas de Luiz Fernando Verissimo. Entre as canções selecionadas para estudos estão as de Beth Carvalho, Legião Urbana, Bezerra da Silva, entre outros autores e 
intérpretes. A abordagem a autores estrangeiros, segundo a professora, fica a cargo dos filhos, netos, enteados dos alunos da EJA - público infantojuvenil -, com procura de livros como, por exemplo, Diário de um banana, Crepúsculo e Como eu era antes de você, todos disponíveis para empréstimo domiciliar na biblioteca.

A professora já percebe os resultados da oficina, pois há melhoria no desempenho dos alunos e também demonstração de interesse em procurar livros na biblioteca. Os alunos pedem indicações de livros para eles mesmos e também para os filhos. A oficina está despertando o interesse deles por outros tipos de literatura, uma vez que as solicitações de indicação de outros livros não coincidem com as temáticas já discutidas. Os professores de outras disciplinas dão feedback positivo sobre a influência da oficina no desempenho dos alunos, chamando a atenção para a melhora significativa observada em leitura, interpretação e até na dicção do grupo participante. A internet também tem sido utilizada para trabalhar as diferentes formas de transmitir notícias e informações, buscando mostrar que nem sempre as informações divulgadas são totalmente verdadeiras, como, por exemplo, as fake news, e que é preciso ter cuidado na coleta de informações em sites e em outros meios disponíveis na internet.

O coordenador da EJA esclarece que a oficina começou como um projeto de reforço escolar, sob a orientação de um oficineiro de literatura. A ideia era suprir a carência e defasagem demonstradas pelos alunos em leitura, criação de repertório, compreensão e interpretação de textos, entre outros aspectos. Inicialmente, o projeto era executado em sala de aula, não havia a parceria atual com a biblioteca e, segundo ele, isso enriqueceu o desenvolvimento dos trabalhos. Ao firmar essa parceria, a Oficina de Leitura e de Escrita tomou o formato atual e foi prontamente acolhida pelos bibliotecários e funcionários da BEB.

O coordenador confirma que o conteúdo é livre para desenvolvimento do professor, porém esclarece que as oficinas precisam dialogar com o eixo definido para o semestre, que serve para interligar todas as atividades e disciplinas. Na EJA da EPSJV, são definidas três oficinas, e a participação do aluno é obrigatória em uma delas, de sua livre escolha. Essa opção é feita nos primeiros quinze dias do curso. Os alunos, principalmente do Fundamental, sentem mesmo a necessidade de desenvolver a leitura e, com frequência, sua escolha recai na Oficina de Leitura e de Escrita.

Os resultados desse projeto também são visíveis para o coordenador, segundo o qual a oficina tem favorecido a integração e a troca de informações entre os alunos, que aprendem 
Oficina de leitura e escrita para estudantes da Educação de Jovens e Adultos: a relevância da biblioteca escolar como recurso pedagógico

uns com os outros. Além disso, ela proporcionou a eles segurança para leitura em voz alta, para manifestação de opiniões em sala de aula. Os alunos se articulam melhor, principalmente os que apresentam problemas de letramento, o que evidencia que a oficina contribui para a formação de um sujeito crítico. Um aspecto importante é que os alunos passam a se sentir mais parte do ambiente, mais pertencentes aos espaços da escola, especialmente o da biblioteca. Eles passaram a participar mais das atividades da EJA. Atualmente, usam todo o espaço e recursos disponíveis na escola, recebendo a mesma atenção que os demais alunos da EPSJV/Fiocruz.

Na percepção dos bibliotecários da BEB, a falta de familiaridade com o espaço em idades e épocas apropriadas cria uma falsa impressão de que o espaço é restritivo e lhes é negado. Como foi mencionado pelo coordenador do curso, ao utilizar a biblioteca nos encontros da oficina, surgiu para os estudantes da EJA um sentimento de pertencimento ao ambiente. Isso foi constatado pelas estatísticas de uso da biblioteca, tendo em vista que a movimentação, a consulta e o empréstimo domiciliar de livros aumentaram consideravelmente após o início da Oficina. Houve inclusive depoimento de alguns alunos que diziam passar na porta da biblioteca e, apesar da curiosidade, não sabiam que podiam entrar e utilizar o espaço.

Assim, foi considerado oportuno oferecer novas atividades na biblioteca envolvendo esses alunos, treinando inclusive suas habilidades de pesquisa e busca de informações, visando demonstrar que é um espaço democrático, de exercício da cidadania, dedicado não só a estudantes de níveis mais avançados, como também a eles e à comunidade em geral.

\section{Conclusão}

A leitura segue sendo importante atributo na sociedade atual, com amplo alcance da difusão de mídias escritas em diferentes suportes. Cidadãos que não conseguem ler e interpretar textos enfrentam dificuldades para se comunicar adequadamente e para compreender regras e normas de convivência diária e outras mais amplas, relativas à vida em sociedade e a direitos e deveres.

Essa importância é reconhecida por indivíduos de diferentes faixas etárias, que buscam expandir suas experiências existenciais de acordo com sua realidade e vivências, inclusive aqueles que não tiveram a oportunidade de frequentar escolas em idade adequada e retornam 
às escolas e à educação formal ali oferecida na modalidade de Educação de Jovens e Adultos (EJA), tanto em nível de Ensino Fundamental quanto de Ensino Médio.

A EJA da Escola Politécnica de Saúde Joaquim Venâncio, da Fundação Oswaldo Cruz, tem dado sua contribuição para a inclusão de uma população carente e especial, pertencente às comunidades do seu entorno. Como se pode observar pelos dados apresentados, o alunado da EJA da ESPJV/Fiocruz se enquadra na descrição da literatura, mostrando um contingente de faixa etária mais alta no Ensino Fundamental em relação ao Ensino Médio. Também em conformidade com as disposições da LDBEN, a oficina busca diversificar a abordagem textual de acordo com a realidade do alunado, privilegiando autores nacionais na seleção de textos e músicas.

Um aspecto relevante na formatação da Oficina de Leitura e Escrita é a parceria com a Biblioteca Emília Bustamante, que evidencia a sua importância como instrumento pedagógico e possibilita aos alunos, além do auxílio dos bibliotecários, o acesso a todos os recursos ali disponíveis, sem qualquer limitação.

Ainda, o alunado da EJA é integrado à EPSJV, como os demais alunos da PósGraduação e do Ensino Médio Técnico, sendo-lhes ofertado o mesmo tratamento, acesso a recursos, treinamentos, inclusive alimentação. Essa integração parece estar sendo bem recebida, assim como a Oficina, uma vez que os alunos da EJA se sentem à vontade para solicitar indicação de leitura para si e para seus familiares, bem como indicar novos títulos para aquisição. Essa conduta, possivelmente, resultará em um círculo virtuoso, com ampliação do interesse pelo uso da biblioteca e do prazer da leitura, envolvendo inclusive o grupo familiar.

Conclui-se, diante do exposto, que a Oficina de Leitura e de Escrita, realizada na Biblioteca Emília Bustamante e direcionada aos alunos da Educação de Jovens e Adultos dos níveis de Ensino Fundamental e Médio, além dos impactos e benefícios já mensurados, ratifica a missão da BEB (2019), de atuar de forma transversal às atividades de Ensino e Pesquisa da Instituição, atendendo todas as necessidades informacionais de estudantes, professores e pesquisadores da EPSJV, bem como da comunidade externa, através do desenvolvimento de projetos educacionais e processos que viabilizem a disponibilização, o acesso e o uso da informação, assim como a compreensão da mesma, para a constante construção do conhecimento e do exercício da cidadania. 
Oficina de leitura e escrita para estudantes da Educação de Jovens e Adultos: a relevância da biblioteca escolar como recurso pedagógico

Bibl. Esc. em R., Ribeirão Preto, v. 8, n. 1, p. 84-98, 2022. 


\section{Referências}

AGUIAR, I. S. S.; ANDRADE NETA, N. F. A importância da leitura na educação de jovens e adultos: de que tipo de leitura estamos falando? Tear: revista de educação, ciência e tecnologia, Canoas, v. 4, n. 1, p. 1-16, 2015.

AZEVEDO, A. L.; ANTELO, M. M. G.; AZEREDO, R. P. Reforma e readequação do layout da Biblioteca Emília Bustamante/EPSJV/Fiocruz. Revista Brasileira de Biblioteconomia e Documentação, São Paulo, v. 13, n. esp., p. 1633-1646, 2017.

AZEVEDO, A. L.; DUARTE, A. F. L. Educação de usuários de bibliotecas: experiência do projeto 'Biblioteca: aqui pode!' com os alunos da EJA. Rio de Janeiro: BEB, 2019.

BEZERRA, J. E. E. A importância do ato de ler dos alunos da EJA. Cadernos do CNLF, Rio de Janeiro, v. 13, n. 4, p. 109-115, 2009.

\section{BIBLIOTECA EMÍLIA BUSTAMANTE. Regimento Interno da Biblioteca Emília} Bustamante. Rio de Janeiro: EPSJV, 2019.

BRASIL. Lei $\mathbf{n}^{0}$ 9.394, de 20 de dezembro de 1996. Estabelece as diretrizes e bases da educação nacional. Disponível em: http://www.planalto.gov.br/ccivil_03/leis/19394.htm. Acesso em: 2 jul. 2019.

BRAUN, P.; MORAIS, J. F. S.; OLIVEIRA, C. G.; ALMEIDA, M. A. O. Rodas em sala de aula: estratégia de ensino e de aprendizagem nos anos iniciais do ensino fundamental.

Cadernos da Pedagogia, São Carlos, v. 3. n.6, p. 80-91, jul./dez, 2009.

CAMPELLO, B.S. A competência informacional na educação para o século XXI. In:

CAMPELLO, B.S. et al. A biblioteca escolar: temas para uma prática pedagógica. 2. ed. Belo Horizonte: Autêntica, 2003. p. 9-11.

CAMPELLO, B. S. Bibliotecas escolares e biblioteconomia escolar no Brasil. Biblioteca Escolar em Revista, Ribeirão Preto, v. 4, n. 1, p. 1-25, 2015.

CARVALHO, M.C. Escola biblioteca e leitura. In: CAMPELLO, B.S. et al. A biblioteca escolar: temas para uma prática pedagógica. 2. ed. Belo Horizonte: Autêntica, 2003. p. 21-23.

FOUANI, M.; COITO, R. F. A leitura para alunos da EJA: com foco para a formação do leitor $-6^{\circ}$ ao $9^{\circ}$ ano do Ensino Fundamental. Cadernos PDE, Curitiba, v. 1, p. 1-18, 2013.

FRAGOSO, G. M. Biblioteca na escola. Revista ACB: Biblioteconomia em Santa Catarina, Florianópolis, v. 7, n. 1, p. 124-131, 2002.

FUNDAÇÃO OSWALDO CRUZ; ESCOLA POLITÉCNICA DE SAÚDE JOAQUIM VENÂNCIO; REDE CCAP. Plano de curso EJA-Manguinhos. Rio de Janeiro, [201-]).

HOMMERDING, N. M. S. Letramento infantil na biblioteca escolar: desenvolvendo habilidades básicas para futuros leitores competentes. Biblioteca Escolar em Revista, Ribeirão Preto, v. 4, n. 2, p. 33-52, 2016. 
Oficina de leitura e escrita para estudantes da Educação de Jovens e Adultos: a relevância da biblioteca escolar como recurso pedagógico

INSTITUTO BRASILEIRO DE GEOGRAFIA E ESTATÍSTICA. Pesquisa Nacional por Amostra de Domicílios Contínua: Educação 2018. IBGE, 2019.

INTERNATIONAL FEDERATION OF LIBRARY ASSOCIATIONS AND INSTITUTIONS (IFLA). Manifesto IFLA/UNESCO para bibliotecas escolares. Tradução de Neusa Dias de Macedo. São Paulo: IFLA, 2000.

KRUG, F. S. A importância da leitura na formação do leitor. Revista de Educação do IDEAU, Getúlio Vargas, v. 10, n. 22, p. 1-13, jul./dez. 2015.

LAMAS, E. P. R. O texto poético como objecto pedagógico: contributos para a didáctica das língua e literatura maternas. Vila Real: UTAD, 1993.

LEITURA. In: HOUAISS, A.; VILLAR, M. S.; FRANCO, F. M. M. Dicionário Houaiss da língua portuguesa. Rio de Janeiro: Objetiva, 2009.

MARQUEZ, D. N. Aspectos linguísticos (cognitivos) do processo de interpretação textual. 1991. Dissertação (Mestrado em Letras e Linguística) - Universidade Federal de Goiás, Goiânia, 1991.

QUEIROZ, A. M. C. A biblioteca, uma organização sociocultural e instrumento a serviço da educação e cidadania. 2006. 53f. Monografia (Especialização em Metodologia da Educação Superior) - Faculdade Batista Brasileira, Salvador, 2006.

RODA. In: HOUAISS, A.; VILLAR, M. S.; FRANCO, F. M. M. Dicionário Houaiss da língua portuguesa. Rio de Janeiro: Objetiva, 2009.

SANTA ANNA, J. A importância da leitura e as contribuições das instituições: em busca de uma sociedade leitora no Brasil. Pró-Discente: caderno de produção acadêmico-científica, Vitória, v. 23, n. 2, p. 34-53, jul./dez. 2017.

SILVA, E. V.; VENTORIM, S. A condição docente do bibliotecário escolar na educação básica. Biblioteca Escolar em Revista, Ribeirão Preto, v. 4, n. 2, p. 94-108, 2016.

SOARES, M. B. Letramento: um tema em três gêneros. 2. ed. Belo Horizonte: Autêntica, 1998. $125 \mathrm{p}$.

SOUSA, L. D.; CANCELA, L. B.; MACHADO, M. C. A leitura e a literatura na EJA: formação de leitores. Ícone: revista de letras, São Luís de Montes Belos, v. 17, n. 1, p. 17-26, maio 2017. 